\title{
Development and Validation of a Nomogram Predicting The Overall Survival for Patients With Primary Gastric Mucosa-Associated Lymphoid Tissue Lymphoma: A SEER-Based Study
}

\section{Dan Wang}

Southeast University Zhongda Hospital https://orcid.org/0000-0003-4291-1390

Ruihua Shi ( $D$ ruihuashi@126.com )

Southeast University Zhongda Hospital https://orcid.org/0000-0003-4977-8801

\section{Xinlin Shi}

Affiated hopital of Yangzhou university

Wei Xu

Southeast University Zhongda Hospital

\section{Research article}

Keywords: primary gastric MALT lymphoma, nomogram, prognosis, overall survival

Posted Date: December 2nd, 2020

DOI: https://doi.org/10.21203/rs.3.rs-115862/v1

License: (c) (i) This work is licensed under a Creative Commons Attribution 4.0 International License.

Read Full License 


\section{Abstract}

Purpose: To create an effective survival nomogram for patients with primary gastric mucosa-associated lymphoid tissue (MALT) lymphoma (GML).

Methods. All data of patients with primary GML from 2004 to 2015 were collected from the Surveillance, Epidemiology and End Results (SEER) database. The primary endpoint was overall survival (OS). Based on the LASSO and COX regression, we created and further verified the accuracy and effectiveness of the survival nomogram model by the concordance index (C-index), calibration curve and time-dependent receiver operating characteristic (td-ROC) curves.

Results. A total of 2604 patients diagnosed with primary GML were selected for this study. A total of 1823 and 781 people were randomly distributed into the training and testing sets at a ratio of 7:3. The median follow-up of all patients was 71 months, and the 3 - and 5 -year OS rates were $87.2 \%$ and $79.8 \%$, respectively. Age, sex, race, Ann Arbor stage and radiation were independent risk factors for OS of primary GML (all $p<0.05)$. The C-index values of the nomogram were 0.751 ( $95 \% \mathrm{Cl}: 0.729-0.773$ ) and 0.718 (95\% Cl: $0.680-0.757)$ in the training and testing cohorts, respectively, showing the good discrimination ability of the nomogram model. Td-ROC curves and calibration plots also indicated satisfactory predictive power and good agreement of the model. Overall, the nomogram shows favorable performance in discriminating and predicting the OS of patients with primary GML.

Conclusions. A nomogram was developed and validated to have good survival predictive performance based on five clinical independent risk factors for OS for patients with primary GML. Nomograms are a low-cost and convenient clinical tool in assessing individualized prognosis and treatment for patients with primary GML.

\section{Introduction}

Increasingly extranodal marginal B-cell lymphoma of mucosa-associated lymphoid tissue, known as MALT lymphoma, is a type of non-Hodgkin's lymphoma[1, 2]. Approximately one-third of cases of MALT lymphoma and $85 \%$ of gastrointestinal MALT lymphomas present in the stomach as the affected site[3, 4]. Primary gastric mucosa-associated lymphoid tissue (MALT) lymphoma (GML) has a rare incidence and only accounts for approximately $5 \%$ of all primary gastric neoplasms [5].

This disease demands high attention. Researchers have observed that GML patients had significant risk of atrophic gastritis, intestinal metaplasia[6, 7] and secondary tumors[8]. Compared to the healthy population, the incidence of gastric adenocarcinoma in GML patients was 6 times higher in the GML population $[9,10]$.

The prognosis of primary GML patients can be affected by many factors. Clinical risk factors, including age, type of therapy, sex, stage and family hematologic malignancy history, also have significant effects on the development of the disease[11-14]. Meanwhile, previous studies demonstrated a good prognosis 
of the disease, with 5 -year survival rates of up to $99 \%$. However, more than $95 \%$ of studies were only based on stage I/II patients with a small sample size, and few of them even used different staging standards [15-19]. Matysiak-Budnik, T et al. [11] conducted a multicenter study in France, and $416 \mathrm{GML}$ patients were retrospectively enrolled. They surprisingly found that $25 \%$ of subjects diagnosed at stage III/IV and $11 \%$ of patients obtained missed or false diagnoses, which was similar to other studies [2022].

Furthermore, the available data are mainly focused on epidemiology; in contrast, few studies have investigated the prognostic variables for overall survival (OS) in patients with primary GML. Based on the realities above, we searched a large amount of data on patients diagnosed with primary GML in the SEER database. The aim was to develop and verify a survival nomogram model that can predict the OS prognosis of primary GML by combining prognostic and determinant variables.

\section{Materials And Methods}

\section{Patient selection and data extraction from the SEER database}

The data for our study were extracted from the SEER database (Username: 12262-November 2019, software version: SEER * Stat 8.3.6). Due to the openness of the database, we did not need to obtain approval from the Ethics Committee.

All patients diagnosed with primary GML from 2004 to 2015 were ultimately included in this study. Subjects meeting the following conditions were excluded: (1) hospitalized death and autopsy source patients; (2) patients with tumor history; (3) patients who were not followed up or who were lost follow-up; (4) age at diagnosis < 20; (5) unknown data (race, stage, cause of death); and (6) survival months $<1$.

A total of 2604 selected GML patients were randomly assigned to the training and validation sets with a ratio of 7:3. There were 1823 and 781 people in the two groups, respectively.

The clinical covariates included sex, age, race, primary site, Ann Abor stage, surgery, chemotherapy, and radiation. Data on the survival month and vital status of patients were also analyzed. The primary endpoint was OS.

\section{Establishment And Verification Of The Survival Nomogram}

In the training set, the least absolute shrinkage and selection operator (LASSO) and multivariate Cox proportional hazard regression were combined to identify the significantly correlated prognostic factors that influenced OS. The nomogram model was established based on the above results. Meanwhile, primary GML patients were divided into low- and high-risk groups at the cutoff point of the risk score. 
Scatter plots, forest plots and Kaplan-Meier curves were generated to visually compare the OS times of patients in the two different risk groups.

Internal validation was performed on the patients in the validation set. The discriminatory performance of the model was measured by the concordance index (C-index) value[23]. We also adopted time-dependent receiver operating characteristic (td-ROC) curves to assess the 3- and 5-year OS predictive power of the nomogram. Additionally, calibration plots were applied to compare the agreement between actual and predicted probability.

\section{Data analysis}

Statistical analysis was performed by IBM SPSS version 22.0 (Chicago, IL, USA) and R version 4.0.2. Continuous variables were grouped and transformed into categorical variables and are expressed as frequency and percentage values $(\mathrm{n} / \%)$. The chi-square test was used to compare categorical variables between groups. Two-sided $P$-values $<0.05$ were considered statistically significant.

\section{Results}

\section{Clinical characteristics of subjects}

The specific clinical and pathological characteristics of all enrolled patients and the training and testing groups are presented in Table 1.

Initially, $4475 \mathrm{GML}$ patients were searched in the SEER database. The following populations were excluded: one primary tumor $=$ NO $(n=1408)$, age $<20(n=9)$, unknown race $(n=74)$, unknown stage $(n=$ 317), unknown $\operatorname{COD}(n=16)$, and survival month $<1(n=47)$. In total, 2604 primary GML patients were included in our study. The median survival time was 71 months.

All patients (median age: $65 \mathrm{y}$ old) were divided into three subgroups (age $<45,45-65,>65$, Table 1 ). Compared to patients $<45$ y old $(8.98 \%)$, the $45-65$ y $(39.94 \%)$ group had a higher proportion $(P=0.001$, HR $4.29,95 \% \mathrm{Cl}[1.881-9.815])$. The proportion of patients $>65 \mathrm{y}$ old was $51.08 \%$. In total, $1250(48.00 \%)$ were male, and 2059 (79.07\%) were white. In addition, primary GML could be located in all parts of the stomach and was mostly diagnosed at stage I (2088/80.18\%) according to the Ann Arbor staging system[24]. The numbers of patients who received surgery, chemotherapy and radiation were 184 (7.07\%), $544(20.89 \%)$ and $860(33.03 \%)$, respectively. The 3- and 5-year OS rates of primary GML were $87.2 \%$ and $79.8 \%$, respectively (Fig. $5 \mathrm{~A}$ ).

To establish the nomogram model, 1823 subjects were randomly assigned to the training cohort, while 781 were assigned to the validation cohort. No significant difference in variables was observed between the two groups (all $P>0.05$ ). 


\section{Multivariate Risk Factor Analysis And Establishment Of The Nomogram}

In the training set, the LASSO Cox regression model was adopted to filter risk factors for OS. The results revealed that 5 out of 8 factors were significantly associated with 3- and 5-year OS, and the specific information is listed in Fig. 1 and Table 2. Increased age, male sex, black race and higher disease stage were inversely correlated with survival, while radiation treatment showed a positive correlation with survival (all $P<0.05$ ). Based on the five variables above, we established an efficient survival nomogram to precisely calculate the probability of 3-and 5-year OS in primary GML patients (Fig. 2). In the nomogram, the C-index value was 0.751 (95\% Cl: 0.729-0.773) and demonstrated satisfactory discrimination ability. Patients were separated into high- and low-risk groups according to the median risk score (cutoff: 0.28 , Fig. 3A). A scatter plot (Fig. 3B) visually showed a shorter survival time and a higher mortality rate of high-risk patients. The Kaplan-Meier curve (Fig. 5B) clearly revealed that, compared to the high-risk population, more low-risk patients had a better OS (all $P<0.0001, \mathrm{HR} 0.190,95 \% \mathrm{Cl} 0.153-$ 0.236), which is consistent with the results shown in Fig. 4 (all HR $>2$ ). Td-ROC curves also showed good predictive power of the nomogram assessing the 3 - and 5-year OS. The areas under the curve (AUCs) were 0.727 (Fig. 6A) and 0.734 (Fig. 6B), respectively. Moreover, another analysis, the calibration curves of the model, shown in Fig. 7A-B, confirmed a high agreement between actual and predictive survival proportions. All the above results indicate the good discrimination and predictive capacities of the model.

\section{Internal Validation In The Validation Set}

To better validate the nomogram model, we carried out relevant analysis in the validation set. The C-index of validation patients was 0.718 (95\% Cl: $0.680-0.757)$, indicating good predictive accuracy of the nomogram model. There were significant survival differences between the low- and high-risk groups on Kaplan-Meier curves (HR 0.233, 95\% Cl 0.174-0.312, $P<0.0001$, Fig. 5C). As shown in Fig. 6C-D, the AUC values of the 3 - and 5 -year OS td-ROC curves were 0.689 and 0.715 , respectively, which were similar to the results in the training set, further confirming the reliable predictive ability of the model. The same phenomenon was also observed between the calibration plots in the training and validation groups (Fig. 7C-D). In conclusion, the survival nomogram model displayed a favorable performance to discriminate and predict the OS of primary GML patients in 2 sets.

\section{Discussion}

Primary GML is confirmed as a low-grade, rare incidence rate lesion, and the main risk for the disease is a histological transformation to diffuse large B-cell lymphoma [19, 25]. Studies mostly focus on epidemiology $[26,27]$ and the prognosis affected by different treatment methods of the disease[14, 22, 28 , 29]. Few large studies have reported the relationship between clinical variables and prognostic survival in primary GML. Until now, no available survival model has been established for predicting the prognosis of patients with primary GML. Our study successfully constructed and validated an effective nomogram 
model to predict the overall survival of the disease based on clinical and pathological risk factor analysis. We demonstrated that age, gender, race, Ann Arbor stage and radiation therapy were independent risk factors for OS of primary GML. The nomogram was proven to have good predictive ability for disease prognosis.

Considering the indolent natural development of the disease, long-term and very large follow-up clinical datasets are needed. In our study, all of the data were obtained from the SEER database. This is a national cancer database gathering a large amount of data from different hospitals in the United States, and patient information is strictly managed and reliable[30]. Meanwhile, we developed and validated a survival nomogram. In recent years, nomograms have been widely used as an effective tool for cancer prognosis[31-33]. Tailored to the specific information of every patient, the nomogram can visually analyze and present the disease event (such as OS) with a single numerical probability[34]. In summary, on the basis of high-quality data and validation analysis methods, our model has good clinical prediction ability and can be applied to clinical work.

The 3- and 5-year OS rates calculated in our study were $87.2 \%$ and $79.8 \%$, respectively. In 2019, the first national study was conducted on the general population in France. They confirmed that the 5-year OS of all populations was $79 \%(95 \% \mathrm{Cl}$ [75-83])[11]. This rate is similar to published studies and may reflect a better prognostic outcome of GML disease than other gastric malignancies.

In 2017, Thieblemont et al.[35] generated a novel MALT lymphoma prognostic index (MALT-IPI), including age $\geq 70$ years, elevated LDH levels and Ann Arbor stage III or IV. They concluded that this index would be an effective method to predict poor outcome for MALT lymphoma. A similar conclusion was found in other studies[11, 14, 19, 29]. T. Matysiak-Budnik et al. [11] conducted a multiple retrospective study in French, including 416 cases of GML. They found that 5-year OS was better for patients $<67 \mathrm{y}$ old $(93.6 \%)$ than for those with an older age $(93.6 \%$ vs $68.5 \%, P<0.0001)$. Another multicenter cohort follow-up study of 420 patients found that age (each incremental year) was an independent prognostic factor for OS ( $P=$ 0.024)[14]. In our study, age had the highest risk and showed a significant correlation with the prognosis of primary GML $(P<0.0001, \mathrm{HR} 19.843)$. The nomogram obviously indicated that increased age, especially $>65 \mathrm{y}$ old, had a negative impact on the OS of the disease. Although several researchers found no association between them[20,29], an insufficient number of subjects in these studies need to be considered. Therefore, we still insist that age and prognosis are closely related. Regardless of the specific cutoff point of age, it is recognized that advanced age means an increased risk of primary GML[13]. Multiple analysis also indicated that Ann Arbor stage was a significant independent prognostic factor for the disease. In our study, most patients presented with stage I-II disease (89.9\%), and as the severity of the disease increased, the prognosis of the disease worsened (all $P<0.05$ ). The proportion of patients with localized and advanced disease at diagnosis varies among reported series[11, 14, 36], and we have a consensus that the prognosis of these patients is different[13].

The percentage of female patients was higher than that of male patients ( $52.0 \%$ vs $48.0 \%)$, and more people were white $(79.07 \%)$. Statistically significant correlations were found between male sex $(P<$ 
$0.001)$, black race $(P=0.036)$ and primary $\mathrm{GML}$ overall survival. Whether sex is related to the disease remains controversial. Some studies have reported that males have a 2-3 times higher incidence rate of development and a worse prognosis than females[37, 38], while other studies have not[11,35]. Until now, no study has focused on the relationship between race and primary GML. SEER provided us with detailed race data and indicated that black individuals are more likely to develop primary $\mathrm{GML}$ (HR $1.374,95 \% \mathrm{Cl}$ 1.020-1.779). We still need more studies to further investigate prognostic factors in primary GML.

Management and treatment guidelines for MALT lymphomas have been extremely heterogeneous until the last few years. Over the past 2-3 decades, eradiation of $H$. pylori has been the preferred choice for GML regardless of the histological status of $H$. pylori[21, 39]. Chemotherapy and radiation therapy (RT) were only suggested to be second-line therapies for nonresponders or advanced patients[39]. In contrast, ESMO guidelines suggested that RT might be the first option for GML patients with localized stages, and chemotherapy was an effective method in patients with all stages.[40] Radiation therapy alone was also reported to have excellent treatment effects on GML with a total dose of 24-30 Gy [29, 41]. Compared with other therapy methods, surgery showed no advantage over treatments in other trials[42]. In our study, no survival difference was found between patients with medication and surgical treatment. Multivariate analysis showed that only RT was significantly associated with better disease prognosis $(P<0.001)$. These data are consistent with previous studies of RT for gastric MALT lymphoma. In total, radiotherapy is a good choice for primary GML disease.

The limitations of this study are very obvious. First, this is a retrospective analysis. All information is from 2004-2015, and part of the data was recorded before the publication of guidelines for primary GML. This may cause heterogeneity in the clinical management of patients, resulting in data bias. Second, SEER cannot provide us with specific details of treatment methods. Some data even show unknown labels. Third, we have no external verification data. We collected a few cases of primary GML, but they are not worth analyzing considering analysis errors. More multiple, prospective datasets of primary GML are still necessary for further investigation.

\section{Conclusion}

In conclusion, a nomogram was developed and validated to have good survival predictive performance based on five clinical independent risk factors for OS for primary GML patients. Nomograms are a lowcost and convenient clinical tool in assessing individualized prognosis and treatment for patients with primary GML.

\section{Abbreviations}

MALT: gastric mucosa-associated lymphoid tissue; GML: gastric mucosa-associated lymphoid tissue lymphoma; SEER: Epidemiology and End Results; OS: overall survival; LASSO: the least absolute shrinkage and selection operator; C-index: concordance index; td-ROC: time-dependent receiver operating characteristic; AUC: areas under the curve; RT: radiation therapy. 


\section{Declarations}

\section{Ethics approval and consent to participate}

Not applicable.

\section{Consent for publication}

Not applicable.

\section{Availability of data and materials}

All data generated or analysed during this study are included in this published article [and its supplementary information files].

\section{Competing interests}

All authors declare no conflict of interest in this study.

\section{Funding}

This work was supported by the National Natural Science Foundation of China (NSFC; Grant No. 30770991).

\section{Authors' Contributions}

Ruihua Shi and Dan Wang designed this study. Collection and analysis of data: Dan Wang, Xinlin Shi. Manuscript writing and drafting: Dan Wang. Ruihua Shi and Lei Xu reviewed the manuscript. Approval of manuscript: All authors.

\section{Acknowledgements}

All people participated in this article are listed in the author listing. Not applicable.

\section{Conflict of Interest}

All authors of this paper have no conflict of interests to disclose.

\section{References}

1. Swerdlow SH, Campo E, Pileri SA, Harris NL, Stein H, Siebert R, Advani R, Ghielmini M, Salles GA, Zelenetz AD, et al. The 2016 revision of the World Health Organization classification of lymphoid neoplasms. Blood. 2016;127(20):2375-90.

2. Chiu BC, Weisenburger DD. An update of the epidemiology of non-Hodgkin's lymphoma. Clin Lymphoma. 2003;4(3):161-8. 
3. Bertoni F, Coiffier B, Salles G, Stathis A, Traverse-Glehen A, Thieblemont C, Zucca E. MALT Lymphomas: Pathogenesis Can Drive Treatment. Oncology-Ny. 2011;25(12):1134-+.

4. Cook JRM-HH, Isaacson PG, et al: Extranodal marginal zone lymphoma of lymphoma of- mucosaassociated lymphoid tissue (MALT) lymphoma. In: Swerdlow SH, Campo.

\section{Harris E. NL et al (eds) WHO classification of tumours of haematopoietic and lymphoid} tissues, Revised 4t, Lyon. IARC 2017:259-262.

6. Müller AMIG, Mertelsmann R, Engelhardt M. Epidemiology of non-Hodgkin's lymphoma (NHL): trends, geographic distribution, and etiology. Annals of hematology. 2005;84(1):1-12.

7. Rentien AL, Levy M, Copie-Bergman C, Gagniere C, Dupuis J, Le Baleur Y, Belhadj K, Sobhani I, Haioun $\mathrm{C}$, Delchier JC, et al. Long-term course of precancerous lesions arising in patients with gastric MALT lymphoma. Digestive liver disease: official journal of the Italian Society of Gastroenterology the Italian Association for the Study of the Liver. 2018;50(2):181-8.

8. Capelle LG, dHC, de Vries AC, Biermann K, Casparie MK, Meijer GA, Kuipers EJ. Premalignant gastric lesions in patients with gastric mucosa-associated lymphoid tissue lymphoma and metachronous gastric adenocarcinoma: a case-control study. Eur J Gastroenterol Hepatol. 2012;24(1):42-7.

9. Tajika M, Matsuo K, Ito H, Chihara D, Bhatia V, Kondo S, Tanaka T, Mizuno N, Hara K, Hijioka S, et al. Risk of second malignancies in patients with gastric marginal zone lymphomas of mucosa associate lymphoid tissue (MALT). J Gastroenterol. 2014;49(5):843-52.

10. Capelle LG, de Vries AC, Looman CW, Casparie MK, Boot H, Meijer GA, Kuipers EJ. Gastric MALT lymphoma: epidemiology and high adenocarcinoma risk in a nation-wide study. Eur $\mathrm{J}$ Cancer. 2008;44(16):2470-6.

11. Copie-Bergman C, Locher C, Levy M, Chaumette MT, Haioun C, Delfau-Larue MH, Leroy K, Gaulard P, Delchier JC. Metachronous gastric MALT lymphoma and early gastric cancer: is residual lymphoma a risk factor for the development of gastric carcinoma? Annals of oncology: official journal of the European Society for Medical Oncology. 2005;16(8):1232-6.

12. Matysiak-Budnik T, Jamet $P$, Ruskone-Fourmestraux $A$, de Mascarel $A$, Velten $M$, Maynadie $M$, Woronoff AS, Tretarre B, Marrer E, Delafosse P, et al. Gastric MALT lymphoma in a population-based study in France: clinical features, treatments and survival. Aliment Pharmacol Ther. 2019;50(6):65463.

13. Wohrer S, Troch M, Streubel B, Zwerina J, Skrabs C, Formanek M, Hauff W, Hoffmann M, Mullauer L, Chott A, et al. MALT lymphoma in patients with autoimmune diseases: a comparative analysis of characteristics and clinical course. Leukemia. 2007;21(8):1812-8.

14. Raderer M, Kiesewetter B, Ferreri AJ. Clinicopathologic characteristics and treatment of marginal zone lymphoma of mucosa-associated lymphoid tissue (MALT lymphoma). CA Cancer J Clin. 2016;66(2):153-71.

15. Nakamura S, Sugiyama T, Matsumoto T, lijima K, Ono S, Tajika M, Tari A, Kitadai Y, Matsumoto H, Nagaya T, et al. Long-term clinical outcome of gastric MALT lymphoma after eradication of 
Helicobacter pylori: a multicentre cohort follow-up study of 420 patients in Japan. Gut. 2012;61(4):507-13.

16. Abe S, Oda I, Inaba K, Suzuki H, Yoshinaga S, Nonaka S, Morota M, Murakami N, Itami J, Kobayashi $\mathrm{Y}$, et al. A retrospective study of 5-year outcomes of radiotherapy for gastric mucosa-associated lymphoid tissue lymphoma refractory to Helicobacter pylori eradication therapy. Jpn J Clin Oncol. 2013;43(9):917-22.

17. Fischbach W, Goebeler-Kolve ME, Dragosics B, Greiner A, Stolte M. Long term outcome of patients with gastric marginal zone B cell lymphoma of mucosa associated lymphoid tissue (MALT) following exclusive Helicobacter pylori eradication therapy: experience from a large prospective series. Gut. 2004;53(1):34-7.

18. Goda JS, Gospodarowicz M, Pintilie M, Wells W, Hodgson DC, Sun A, Crump M, Tsang RW. Long-term outcome in localized extranodal mucosa-associated lymphoid tissue lymphomas treated with radiotherapy. Cancer. 2010;116(16):3815-24.

19. Jager G, Neumeister P, Quehenberger F, Wohrer S, Linkesch W, Raderer M. Prolonged clinical remission in patients with extranodal marginal zone B-cell lymphoma of the mucosa-associated lymphoid tissue type treated with cladribine: 6 year follow-up of a phase II trial. Annals of oncology: official journal of the European Society for Medical Oncology. 2006;17(11):1722-3.

20. Stathis A, Chini C, Bertoni F, Proserpio I, Capella C, Mazzucchelli L, Pedrinis E, Cavalli F, Pinotti G, Zucca E. Long-term outcome following Helicobacter pylori eradication in a retrospective study of 105 patients with localized gastric marginal zone B-cell lymphoma of MALT type. Annals of oncology: official journal of the European Society for Medical Oncology. 2009;20(6):1086-93.

21. Wang YG, Zhao LY, Liu CQ, Pan SC, Chen XL, Liu K, Zhang WH, Yang K, Chen XZ, Zhang B, et al. Clinical characteristics and prognostic factors of primary gastric lymphoma: A retrospective study with 165 cases. Medicine. 2016;95(31):e4250.

22. Hu Q, Zhang Y, Zhang X, Fu K. Gastric mucosa-associated lymphoid tissue lymphoma and Helicobacter pylori infection: a review of current diagnosis and management. Biomark Res. 2016;4:15.

23. Todorovic M, Balint B, Jevtic M, Suvajdzic N, Ceric A, Stamatovic D, Markovic O, Perunicic M, Marjanovic S, Krstic M. Primary gastric mucosa associated lymphoid tissue lymphoma: clinical data predicted treatment outcome. World J Gastroenterol. 2008;14(15):2388-93.

24. Gonen M, Heller G. Concordance probability and discriminatory power in proportional hazards regression. Biometrika. 2005;92(4):965-70.

25. K M: Clinical staging classification of non-Hodgkin's lym-phomas (author's transl). Strahlentherapie 1977, 153:218-221.

26. Maeshima AM, Taniguchi H, Toyoda K, Yamauchi N, Makita S, Fukuhara S, Munakata W, Maruyama D, Kobayashi Y, Tobinai K. Clinicopathological features of histological transformation from extranodal marginal zone B-cell lymphoma of mucosa-associated lymphoid tissue to diffuse large Bcell lymphoma: an analysis of 467 patients. Br J Haematol. 2016;174(6):923-31. 
27. Palmela C, Fonseca C, Faria R, Baptista RB, Ribeiro S, Ferreira AO. Increased risk for metachronous gastric adenocarcinoma following gastric MALT lymphoma-A US population-based study. United European Gastroenterol J. 2017;5(4):473-8.

28. Luminari S, Cesaretti M, Marcheselli L, Rashid I, Madrigali S, Maiorana A, Federico M. Decreasing incidence of gastric MALT lymphomas in the era of anti-Helicobacter pylori interventions: results from a population-based study on extranodal marginal zone lymphomas. Annals of oncology: official journal of the European Society for Medical Oncology. 2010;21(4):855-9.

29. Fischbach W, Goebeler ME, Ruskone-Fourmestraux A, Wundisch T, Neubauer A, Raderer M, Savio A, Group E. Most patients with minimal histological residuals of gastric MALT lymphoma after successful eradication of Helicobacter pylori can be managed safely by a watch and wait strategy: experience from a large international series. Gut. 2007;56(12):1685-7.

30. Wirth A, Gospodarowicz M, Aleman BM, Bressel M, Ng A, Chao M, Hoppe RT, Thieblemont C, Tsang R, Moser $L$, et al. Long-term outcome for gastric marginal zone lymphoma treated with radiotherapy: a retrospective, multi-centre, International Extranodal Lymphoma Study Group study. Annals of oncology: official journal of the European Society for Medical Oncology. 2013;24(5):1344-51.

31. Surveillance E, REh, Accessed August 15: (SEER) Program Research Data (1973-2013), National Cancer Institute, DCCPS, Surveillance Research Program, Surveillance Systems Branch, released April 2016, based on the November 2015 submission. http://wwwseercancergov Accessed August 15, 2016.

32. Gold JS, Gonen M, Gutierrez A, Broto JM, Garcia-del-Muro X, Smyrk TC, Maki RG, Singer S, Brennan $M F$, Antonescu $C R$, et al. Development and validation of a prognostic nomogram for recurrence-free survival after complete surgical resection of localised primary gastrointestinal stromal tumour: a retrospective analysis. The Lancet Oncology. 2009;10(11):1045-52.

33. Tang X, Zhou X, Li Y, Tian X, Wang Y, Huang M, Ren L, Zhou L, Ding Z, Zhu J, et al. A Novel Nomogram and Risk Classification System Predicting the Cancer-Specific Survival of Patients with Initially Diagnosed Metastatic Esophageal Cancer: A SEER-Based Study. Ann Surg Oncol. 2019;26(2):321-8.

34. Hirabayashi S, Kosugi S, Isobe Y, Nashimoto A, Oda I, Hayashi K, Miyashiro I, Tsujitani S, Kodera Y, Seto $Y$, et al. Development and external validation of a nomogram for overall survival after curative resection in serosa-negative, locally advanced gastric cancer. Annals of oncology: official journal of the European Society for Medical Oncology. 2014;25(6):1179-84.

35. Iasonos A, Schrag D, Raj GV, Panageas KS. How to build and interpret a nomogram for cancer prognosis. Journal of clinical oncology: official journal of the American Society of Clinical Oncology. 2008;26(8):1364-70.

36. Thieblemont C, Cascione L, Conconi A, Kiesewetter B, Raderer M, Gaidano G, Martelli M, Laszlo D, Coiffier B, Lopez Guillermo A, et al. A MALT lymphoma prognostic index. Blood. 2017;130(12):140917. 
37. Ruskone-Fourmestraux A, Lavergne A, Aegerter PH, Megraud F, Palazzo L, de Mascarel A, Molina T, Rambaud JL. Predictive factors for regression of gastric MALT lymphoma after anti-Helicobacter pylori treatment. Gut. 2001;48(3):297-303.

38. Cogliatti SB, Schmid U, Schumacher U, Eckert F, Hansmann ML, Hedderich J, Takahashi H, Lennert K. Primary B-cell gastric lymphoma: a clinicopathological study of 145 patients. Gastroenterology. 1991;101(5):1159-70.

39. Juarez-Salcedo LM, Sokol L, Chavez JC, Dalia S. Primary Gastric Lymphoma, Epidemiology, Clinical Diagnosis, and Treatment. Cancer Control. 2018;25(1):1073274818778256.

40. Ruskone-Fourmestraux A, Fischbach W, Aleman BM, Boot H, Du MQ, Megraud F, Montalban C, Raderer M, Savio A, Wotherspoon A, et al. EGILS consensus report. Gastric extranodal marginal zone B-cell lymphoma of MALT. Gut. 2011;60(6):747-58.

41. Zucca E, Copie-Bergman C, Ricardi U, Thieblemont C, Raderer M, Ladetto M, Group EGW. Gastric marginal zone lymphoma of MALT type: ESMO Clinical Practice Guidelines for diagnosis, treatment and follow-up. Annals of oncology: official journal of the European Society for Medical Oncology. 2013;24(Suppl 6):vi144-148.

42. Tsang RW, Gospodarowicz MK. Radiation therapy for localized low-grade non-Hodgkin's lymphomas. Hematol Oncol. 2005;23(1):10-7.

43. Koch P, Probst A, Berdel WE, Willich NA, Reinartz G, Brockmann J, Liersch R, del Valle F, Clasen H, Hirt $C$, et al. Treatment results in localized primary gastric lymphoma: data of patients registered within the German multicenter study (GIT NHL 02/96). Journal of clinical oncology: official journal of the American Society of Clinical Oncology. 2005;23(28):7050-9.

\section{Tables}

Due to technical limitations, table 1 and 2 is only available as a download in the Supplemental Files section.

\section{Figures}



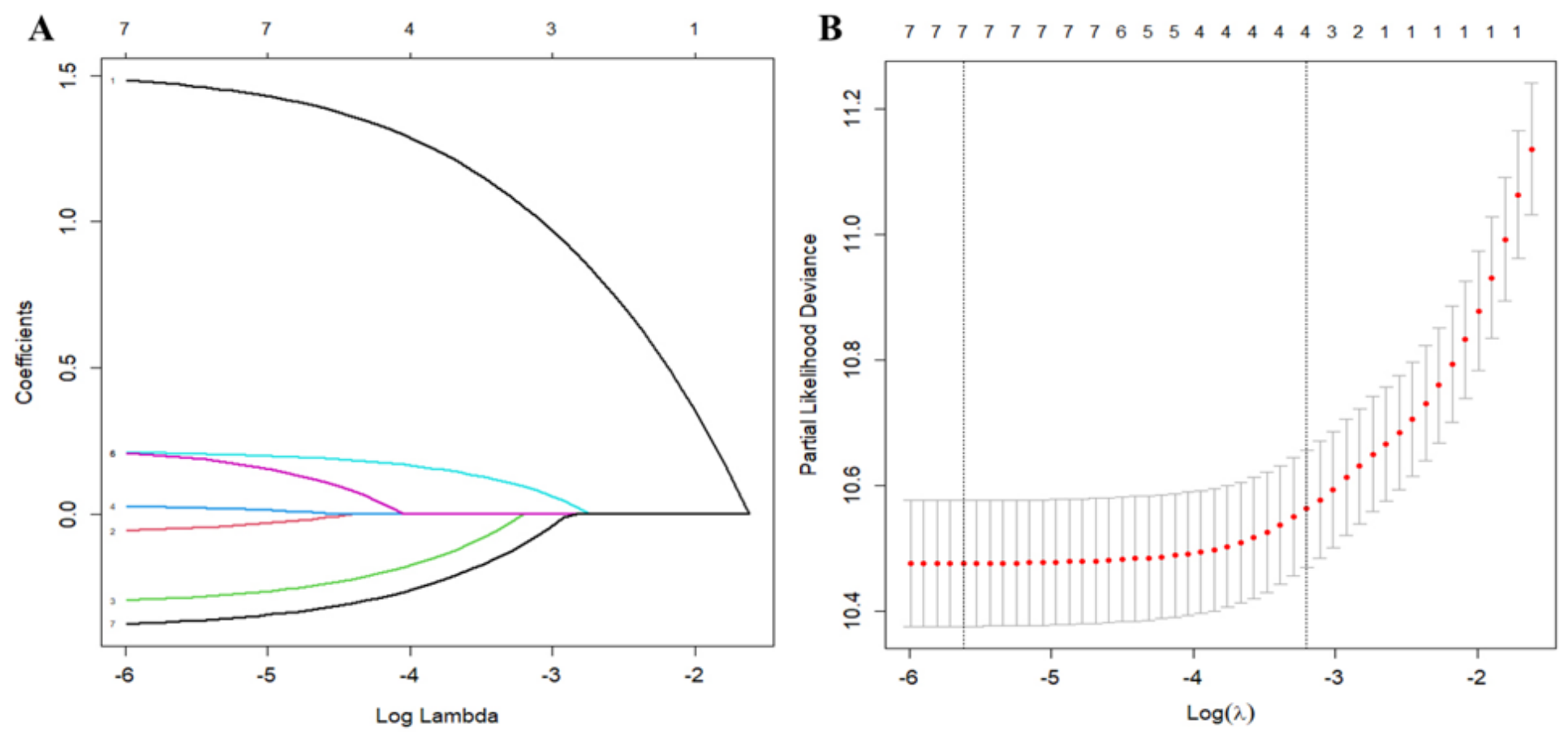

\section{Figure 1}

Identify the correlated prognostic factors by least absolute shrinkage and selection operator (LASSO) regression. (A) LASSO coefficient profiles of the 8 primary GML-associated variables. (B) The selection of optimal prognostic factors by cross-validation. GML, gastric mucosa-associated lymphoid tissue lymphoma. 
Points

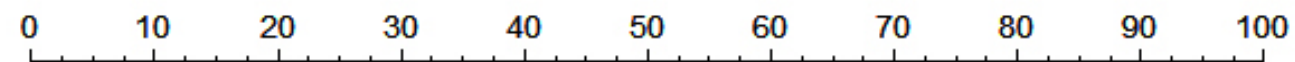

Age

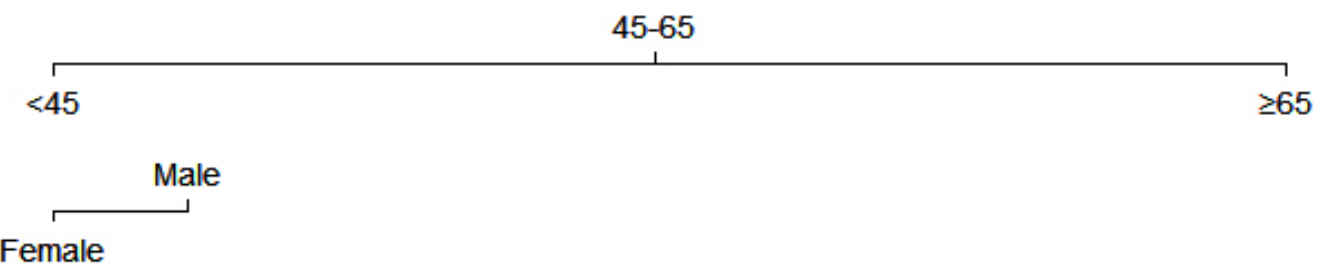

Race

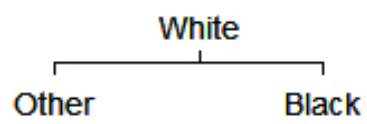

Stage

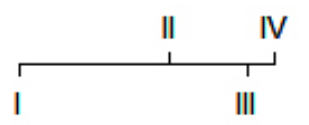

Radiation

No/unknown

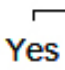

Total Points

\begin{tabular}{|c|c|c|c|c|c|c|c|c|}
\hline & & & 1 & 1 & T & 8 & 1 & 1 \\
\hline 20 & 40 & 60 & 80 & 100 & 120 & 140 & 160 & 180 \\
\hline
\end{tabular}

3-years Survival

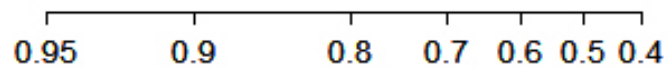

5-years Survival

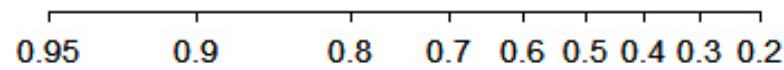

\section{Figure 2}

Survival nomogram for primary GML in 3- and 5-year OS. GML gastric mucosa-associated lymphoid tissue lymphoma; OS, overall survival. 


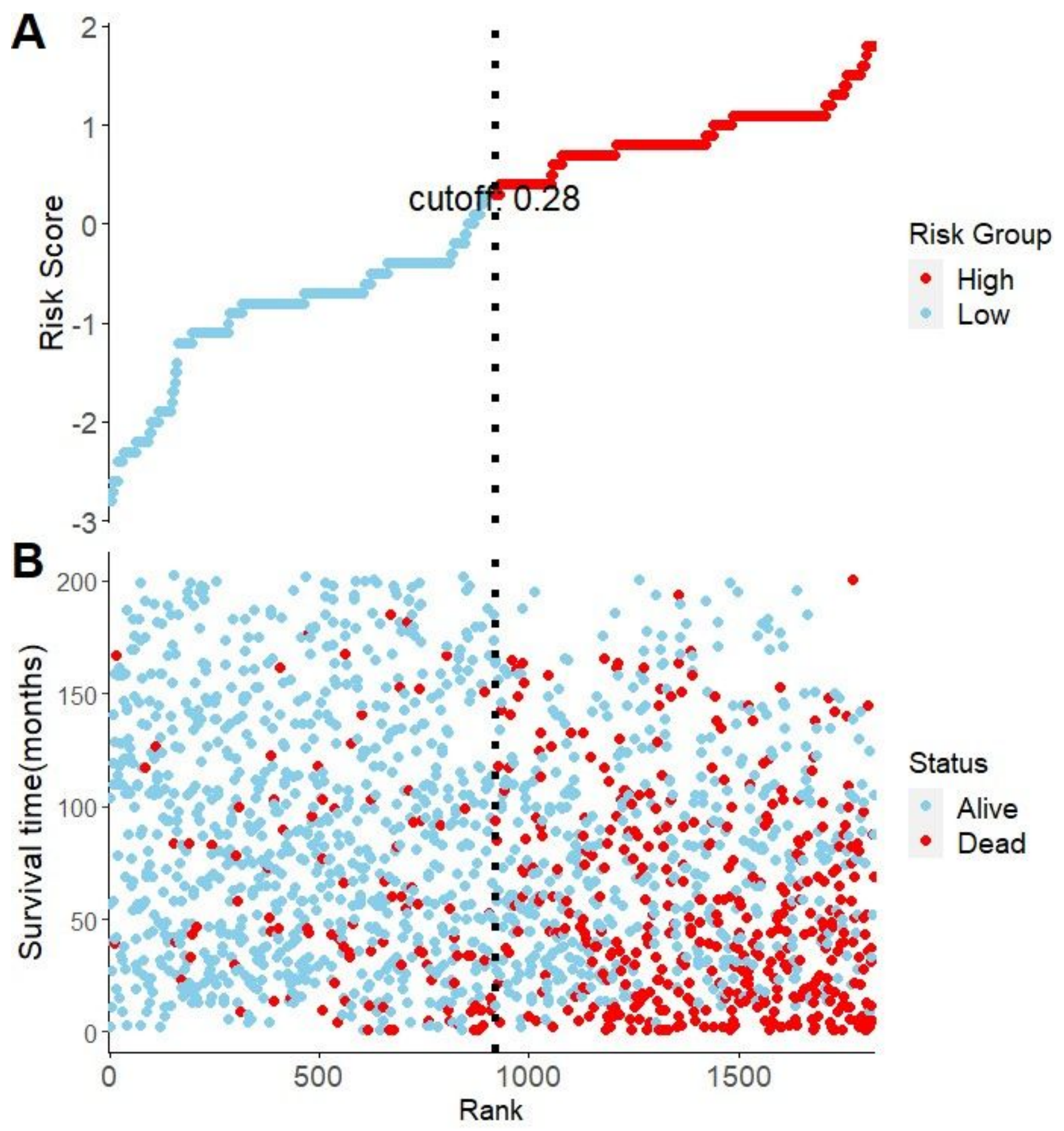

Figure 3

Patients in the training set were separated into high- and low-risk groups (A) according to the Cox regression risk score (cutoff point: 0.28). (B) Scatter plot showing that patient survival time was sorted by risk score; high-risk patients had shorter survival times and higher mortality rates. 
Subgroup High risk(n) Low risk(n)

$\mathrm{HR}(95 \% \mathrm{Cl})$

Age

$\geq 65$

905

11

Sex

Male

410

452

Female

495

466

Race

White

760

674

Black

80

Other

65

121

123

Stage

I

720

732

॥ $\quad 88$

99

III

25

22

IV

72

65

\section{Radiation}

No/unknown

635

596

270

322

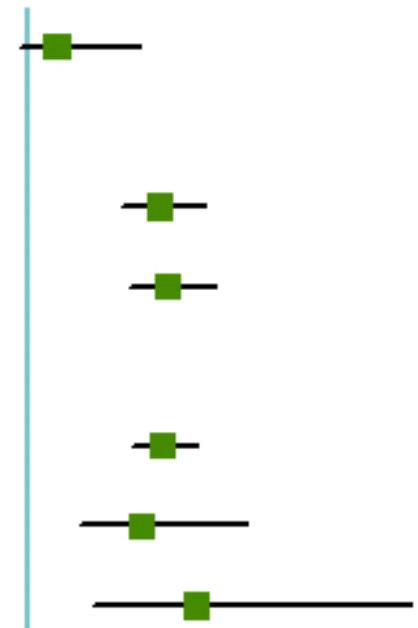

$1.89(0.80-4.46)$

5.03(3.93-6.44)

5.32(4.15-6.80)

5.13(4.24-6.21)

4.47(2.59-7.73)

6.21(3.02-12.80)

5.41(4.42-6.63)

4.48(2.64-7.62)

4.85(1.93-12.22)

3.71(2.24-6.17)

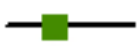

Yes

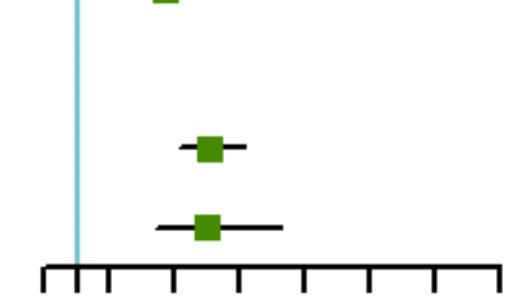

5.07(4.16-6.17)

4.95(3.39-7.24)

$\begin{array}{llllllll}0 & 12 & 4 & 6 & 8 & 10 & 12 & 14\end{array}$

High risk Low risk

\section{Figure 4}

Subgroup analysis results of associations between independent factors and overall survival time between high- and low-risk patients in the training set. 


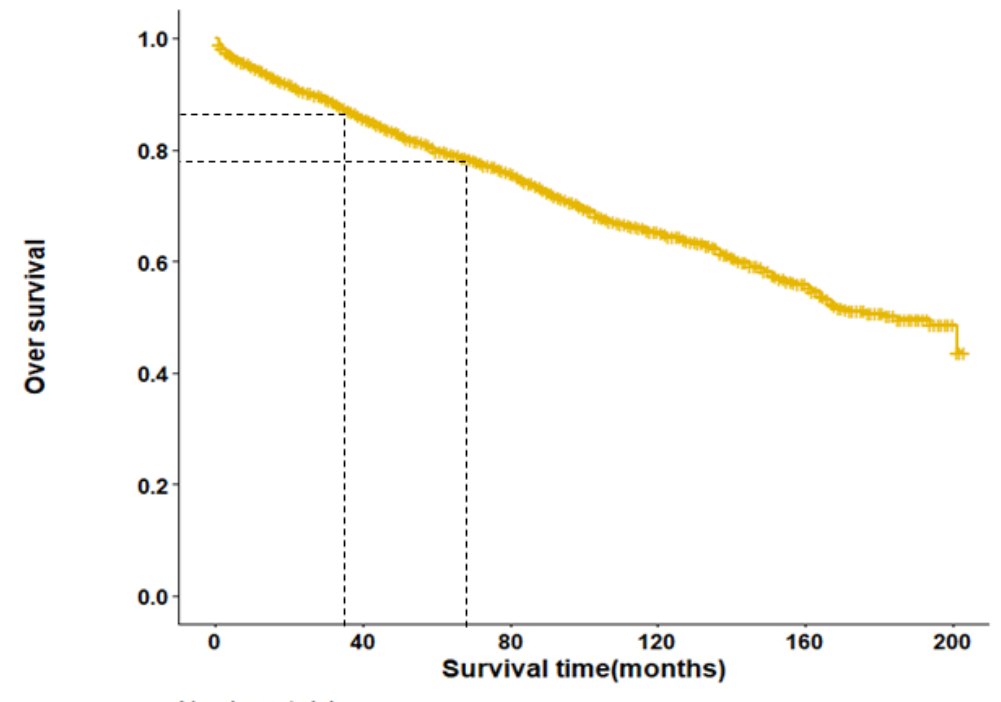

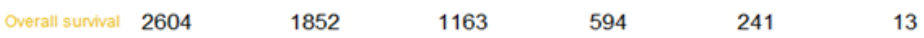
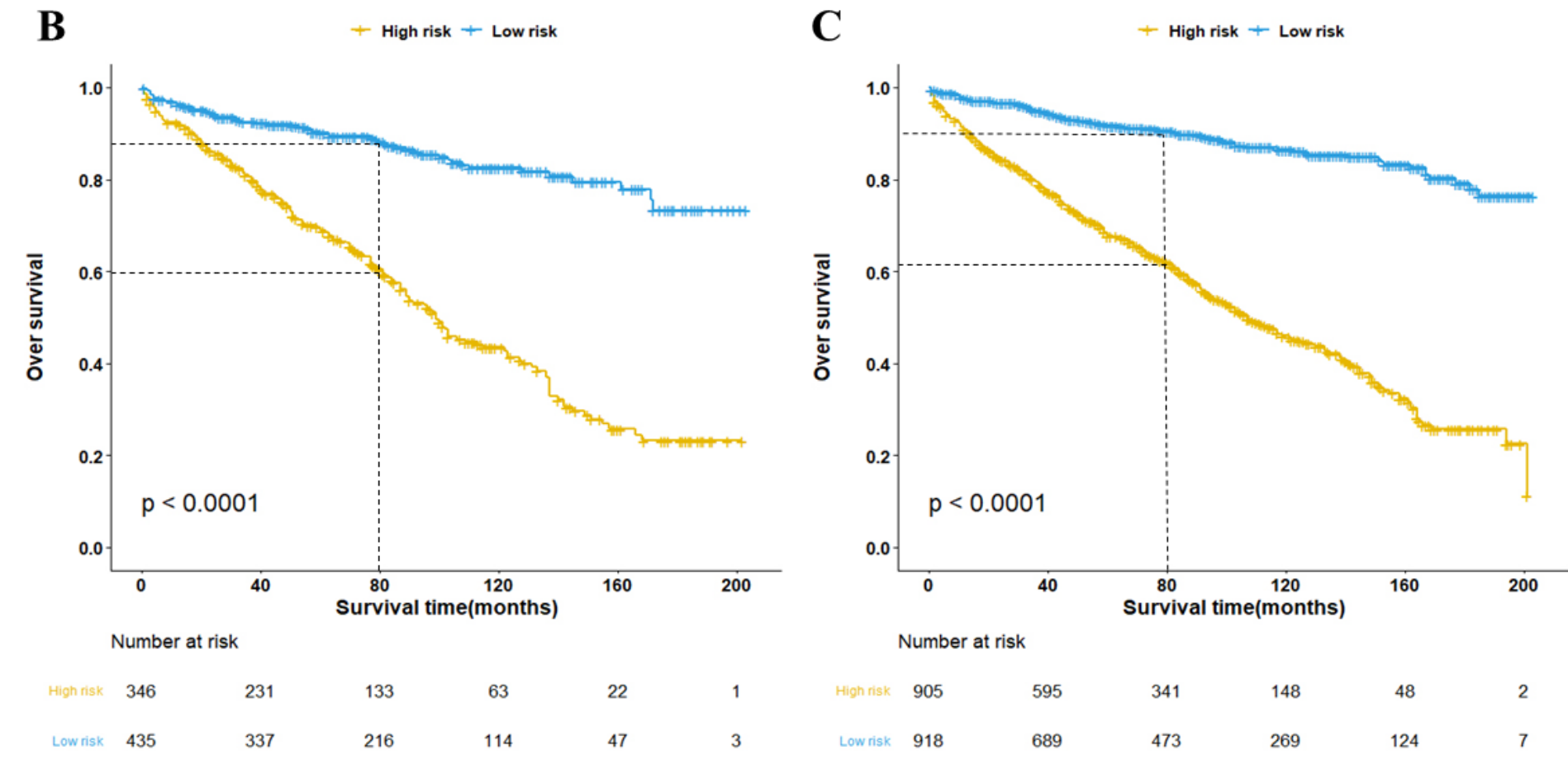

Figure 5

Kaplan-Meier curves of OS for patients in the high- and low-risk groups. Analysis results of all patients $(A)$, the training set $(B)$ and the testing set $(C)$. OS, overall survival. 
A
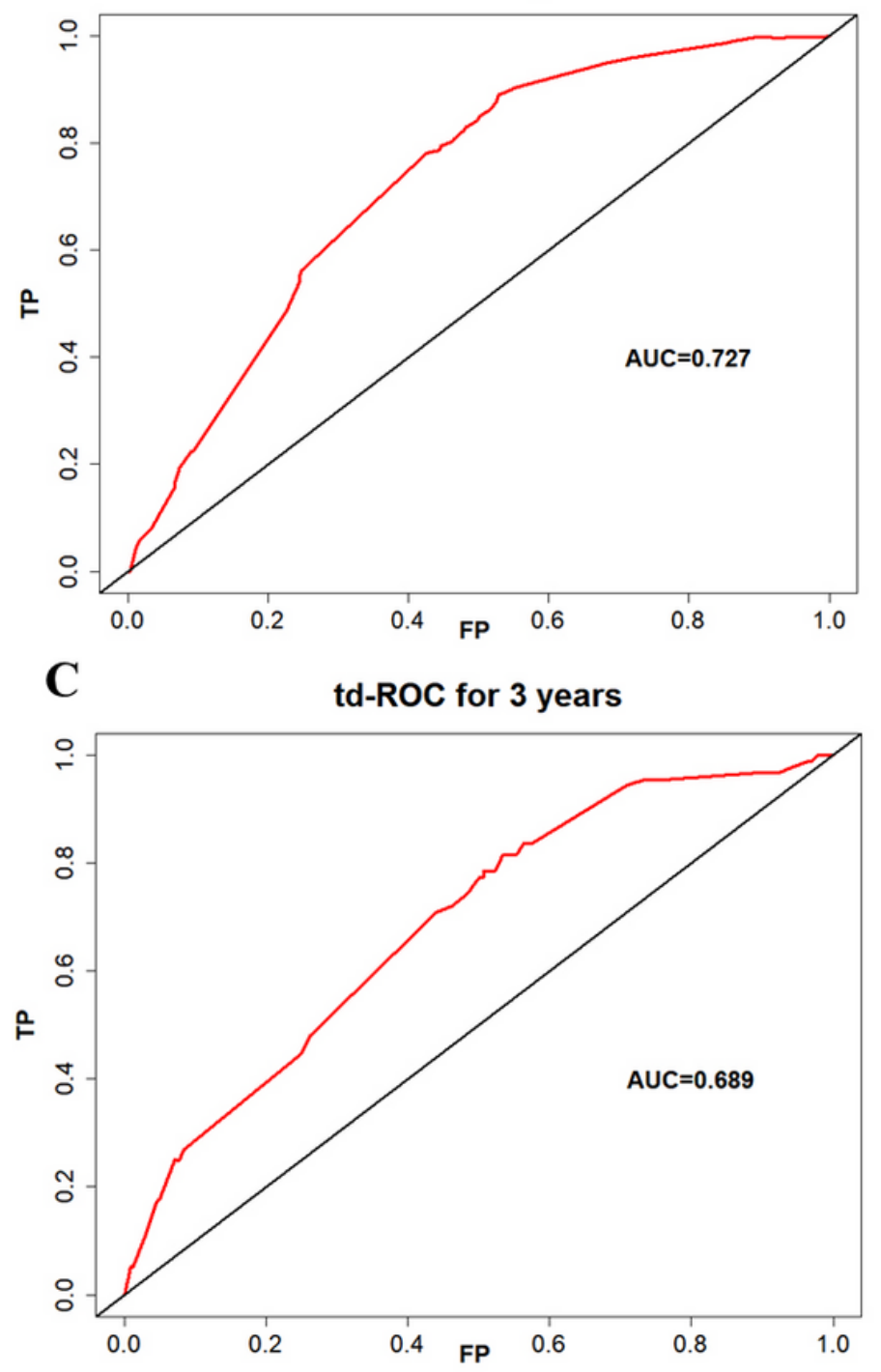

B

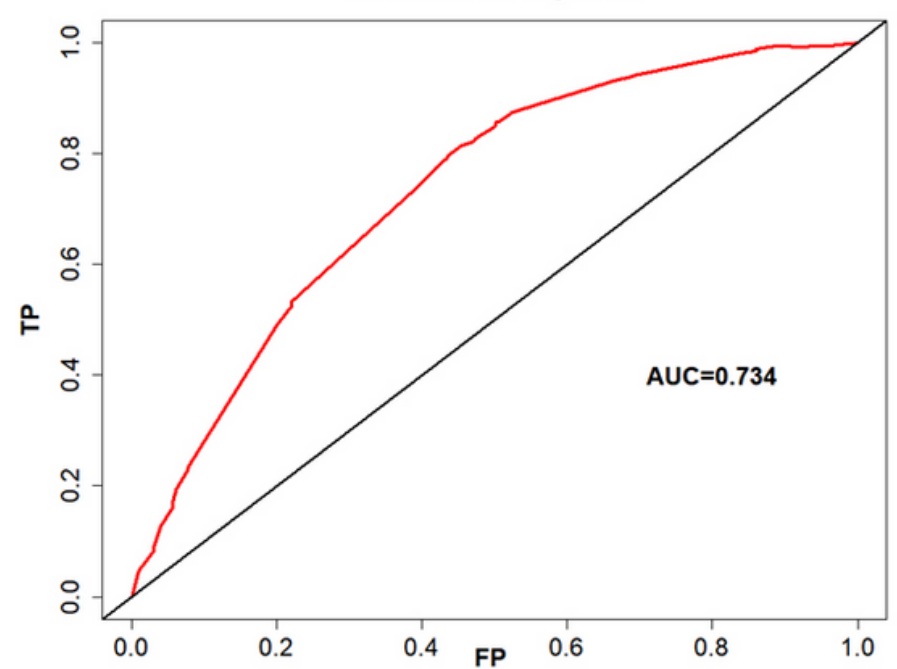

D td-ROC for 5 years

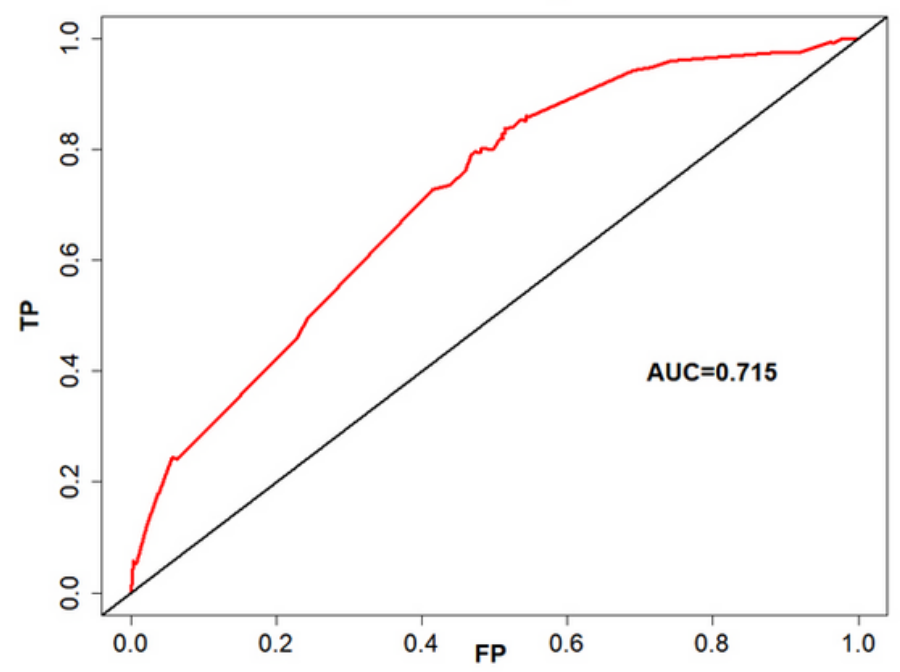

\section{Figure 6}

Td-ROC curves to assess the predictive power of the nomogram. Curves of 3-and 5-year OS in the training set $(A-B)$ and in the validation set (C-D). td-ROC, time-dependent receiver operating characteristic; $O S$, overall survival. 

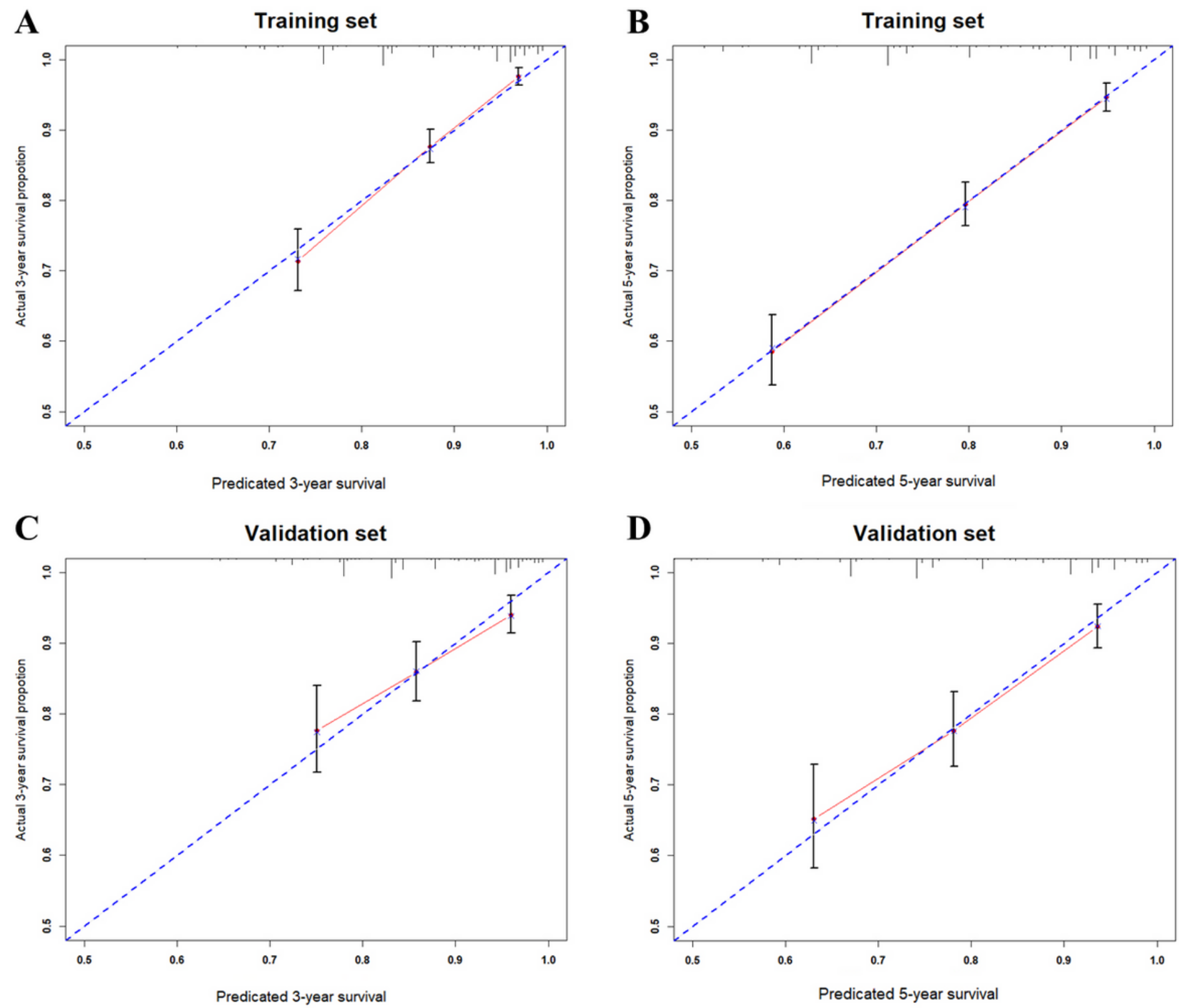

\section{Figure 7}

A calibration plot was applied to compare the agreement between the actual and predicted probability of 3 - and 5-year OS in the training (A-B) and testing sets (C-D), respectively. OS, overall survival.

\section{Supplementary Files}

This is a list of supplementary files associated with this preprint. Click to download.

- Table1.docx

- Table2.docx

- Supplementarymaterial1.LanguageEditingCertificate.pdf 
- Supplementarymaterial2.ConflictofInterestForm.pdf 